\title{
Effect of chitosan as a coupling agent and types of stabiliser of zirconia filler on nanocomposite hardness
}

\author{
Tansza Permata Setiana Putri*, Rosida Manurung**, Kosterman Usri**, Bambang \\ Sunendar Purwasasmita***
}

\author{
*Department of Biomaterials Faculty of Dental Science Kyushu University, Japan \\ **Department of Dental Material Science and Technology Faculty of Dentistry Universitas Padjadjaran, \\ Indonesia \\ ***Advanced Material Processing Laboratory Department of Engineering Physics Faculty of Industrial \\ Technology Bandung Institute of Technology, Indonesia
}

\begin{abstract}
Introduction: Nanocomposite has been developed as a dental restoration. Nano-scale filler can result in high mechanical properties and good esthetic. Nanofiller materials such as partially stabilised $z$ irconia (PSZ) has been recommended for dental use. This form of zirconia can be stabilised by the addition of several different oxides such as magnesia and calcia. Chitosan as a coupling agent was able to increase the nanocomposite's mechanical properties. The purpose of this research was to evaluate the nanocomposite's hardness value with and without the addition of chitosan as a coupling agent as well as a different stabiliser of zirconia filler. Methods: Procedures of this research consisted of several stages which were the fabrication of nanocomposite and mechanical properties measurement using the Vicker's hardness testing. Results: The nanocomposite's hardness value $\left(\mathrm{kg} / \mathrm{mm}^{2}\right)$ with zirconia filler stabilised by $\mathrm{MgO}$ without the addition of chitosan was as much as 5.09 and with the addition of chitosan was 7.51; the nanocomposite's hardness number with zirconia filler stabilised by $\mathrm{CaO}$ without the addition of chitosan was 8.16 and with the addition of chitosan was 13.13. The results were then analysed statistically using the Analysis of Variance (ANOVA) test and showed a significant difference between all of those data groups. Conclusion: The addition of chitosan as well as different stabiliser ( $\mathrm{MgO}$ and $\mathrm{CaO}$ ) of Zirconia filler had affected the nanocomposite 's hardness value.
\end{abstract}

Keywords: Calcia, chitosan, hardness, magnesia, nanocomposite, zirconia.

P-ISSN 1979-0201, e-ISSN 2549-6212 Available from: http://jurnal.unpad.ac.id/pjd/article/view/16101

DOI: 10.24198/pjd.vol30no1.16101

Submission: Dec 2017 Publishing: Mar 2018

\section{INTRODUCTION}

There are four groups of materials used in dentistry: metal, ceramic, polymer, and composite. Materials scientists and dentists continue researching the ideal restorative material. Restorative dental materials contain all synthetic components can be used to repair or replace the teeth structure,

Corresponding author: Tansza Permata Setiana P, Department of Biomaterials Faculty of Dental Science Kyushu University, Japan; M: +81 80-9060-3225; email: tansza.setiana@yahoo.com. 
including bonding agents, liners, cement bases, amalgams, resin-based composites, compomers, hybrid ionomers, cast metals, metal-ceramics, ceramics, and denture polymers. ${ }^{1}$

Composite is one of the restorative materials used in dentistry to replace missing teeth structure and enhancing the aesthetics. Composite resin composed of four major components: organic polymer matrix, with two most common polymer matrix have been used are Bis-GMA and UDMA, added by diluents monomer such as TEGDMA to reached clinical consistency when compounded; anorganic filler such as crystaline quartz, lithium aluminosilicate, barium aluminoborate silica glass, and fused silica as reinforcement compound; coupling agent, such as silanes, which added to earn a very stable adhesive bonding between filler and matrix, thus improving strength and wear resistance; initiators and accelerators, light activation, which accomplished through the blue light with a wavelength peak approximately at $470 \mathrm{~nm}$, which absorbed by an initiator such as camphoroquinone, and an organic amine as the catalyst. ${ }^{2,3}$

The filler particle size and amount affect some properties such as strength and hardness. Therefore, many research on the resin composite were focusing on the filler size. New composites have been developed with nano-sized filler (nanofiller). Nanofiller results in a smooth surface and improved mechanical properties. ${ }^{3-5}$ Many efforts have been done for improving the mechanical properties of the nanocomposite, one of them is using zirconia as the filler. ${ }^{6}$

Ceramic materials such as zirconia have great potential as substitution material for traditional materials in many biomedical applications. Since the end of the 1990s, the form of partially stabilised zirconia (PSZ) has been recommended for dental use due to its excellent strength and superior fracture resistance as a result of an inherent transformation toughening mechanism. This form of PSZ was able to reached when the tetragonal phase was stabilised. Several different oxides, such as magnesium oxide $(\mathrm{MgO})$, yttrium oxide $\left(\mathrm{Y}_{2} \mathrm{O}_{3}\right)$, calcium oxide $(\mathrm{CaO})$, and cerium oxide $\left(\mathrm{Ce}_{2} \mathrm{O}_{3}\right)$, can be added to zirconia to stabilise the tetragonal phases. Based on the economic consideration and the natural availability, in this research, $\mathrm{MgO}$, and $\mathrm{CaO}$ were used as stabilisers. ${ }^{5,6}$ Beside filler modification, there are other efforts to get nanocomposite with improved mechanical properties, one of them is a modification of the coupling agent, which in this research was the addition of chitosan. Chitosan is the $\mathrm{N}$-deacetylated derivative of chitin. It is the second most abundant natural biopolymer after cellulose. Chitosan is nontoxic, biocompatible, and more economical than other synthetic materials. ${ }^{7}$ Chitosan has the adhesive characteristic that forms a good bonding between filler and matrix thus increasing the mechanical properties of the nanocomposite. ${ }^{8,9}$

The hardness property is one of the major importance in the comparison of restorative materials. ${ }^{3}$ To get a composite suitable for dental restoration, it requires hardness that resembles the teeth structure to make the composite having the good wear resistance. Resin composite often tested regarding its ability to substitute the hardness property of amalgam. ${ }^{10}$

Many research has been conducted on improving the hardness of resin composite, such as modification on the filler and also modification on the coupling agent. The purpose of this research was to evaluate the nanocomposite's hardness value with and without the addition of chitosan as a coupling agent as well as a different stabiliser of zirconia filler.

\section{METHODS}

This research was conducted at the Advanced Material Processing Laboratory Department of Engineering Physics Faculty of Industrial Technology, Bandung Institute of Technology, and also National Nuclear Energy Agency of Indonesia (BATAN) in 4 months. There were four specimens of nanocomposite with PSZ filler as follows: A) PSZ filler containing MgO stabiliser with and without chitosan as coupling agent; B) PSZ filler containing $\mathrm{MgO}$ stabiliser without chitosan as coupling agent; C) PSZ filler containing $\mathrm{CaO}$ stabiliser without chitosan as coupling agent; and D) PSZ filler containing $\mathrm{CaO}$ stabiliser with chitosan as coupling agent.

Procedures of this research consisted of several stages which were a fabrication of nanocomposite and the measurement of the nanocomposite's hardness value with HV-1000 
Vickers microhardness testing machine. The powder was mixed with the coupling agent and polymer matrix with the composition of $70 \%$ of PSZ filler and 30\% mixture of the polymer matrix, coupling agent, initiator, and catalyst.

An organic polymer matrix used in this research was UDMA, and the diluents were TEGDMA \& HEMA, champoroquinone was used as the initiator, and DMAEMA was used as the catalyst. Chitosan as the coupling agent was given to the two specimens ( $\mathrm{MgO}$ and $\mathrm{CaO}$ stabilisers), mixed with trimethoxy (propyl) silane, as for the other two specimens were only given trimethoxy (propyl) silane as the coupling agent.

All samples were fabricated by casting the mixture of nanocomposite on the plastic ring with the height of $\Phi 5 \mathrm{~mm}$ and $2 \mathrm{~mm}$, then lightcured with the Woodpecker's LED-D Curing Light for two minutes with the wavelength of $420-480$ nm. Prepared samples then tested with HV-1000 Vickers microhardness testing machine with the test force of $9.8 \mathrm{~N}$ for 15 seconds.

\section{RESULTS}

The final stage of this research was the measurement of the hardness value of all nanocomposite specimens. Figure 1 showed the nanocomposite specimens ready for hardness measurement. Vickers indentor formed a diamondshaped with diagonal of 340-680 $\mu \mathrm{m}$. The smaller the diagonal, the higher the hardness value, vice versa. Hardness values of all nanocomposite specimens were shown in Table 1.

Furthermore, the statistic analysis using the ANOVA test was performed to see significant differences in the hardness value of all nanocomposite specimens, with the results shown in Table 2.

Table 2 shown the hardness value result of all nanocomposite specimens. The hardness value of sample D was 13.13, and based on Table 3, with a degree of freedom 3 (numerator), and 16 (denumerator), the $\mathrm{F}_{\text {critical }}$ was $3.24(\alpha=0.05)$, and the statistic value of $F$ was 30.06 . The hypothesis of this research were as follows: $\mathrm{H}_{0}$ stated that there was no significant difference in the hardness values among all nanocomposite specimens with or without chitosan and different stabilisers ( $\mathrm{MgO}$ and $\mathrm{CaO}$ ) in the PSZ fillers. $\mathrm{H}_{1}$ stated that there was a significant difference in the hardness values among all nanocomposite specimens with or without chitosan and different stabilisers (MgO and $\mathrm{CaO}$ ) in the PSZ fillers.

The $\mathrm{H}_{0}$ was accepted if the $\mathrm{F}$ value was smaller than the $F_{\text {critical }}$. In the result of this research, however, the $F$ value was higher than the $F_{\text {critical }}(30.06>3.24)$ thus $H_{0}$ was rejected, and $H_{1}$ was accepted. It means that there was a significant difference in the hardness values among all specimens. The nanocomposite with chitosan as coupling agent was different from the specimen without chitosan, and nanocomposite with PSZ filler containing MgO stabiliser $\mathrm{MgO}$ was different from the specimen with $\mathrm{CaO}$ stabiliser.

\section{DISCUSSION}

The research results showed that the hardness value of nanocomposite specimen with $\mathrm{MgO}$ stabilised Zirconia filler without chitosan as coupling agent was $5.09 \mathrm{~kg} / \mathrm{mm}^{2}$; MgO-stabilised Zirconia filler with chitosan was $7.51 \mathrm{~kg} / \mathrm{mm}^{2}$; CaO-stabilised Zirconia filler without chitosan was $8.16 \mathrm{~kg} / \mathrm{mm}^{2}$; CaO-stabilised Zirconia filler with chitosan was $13.13 \mathrm{~kg} / \mathrm{mm}^{2}$.

Nanocomposites with addition of chitosan as coupling agent had a higher hardness value than the specimen without chitosan. This result showed that chitosan was significantly increasing the mechanical interlocking between filler and matrix. Adhesive ability of chitosan could produce a strong bonding between filler and matrix which leads to improved composite mechanical properties. ${ }^{11}$

Furthermore, nanocomposites with Zirconia filler contained $\mathrm{CaO}$ stabiliser had a higher hardness value than the specimen contained $\mathrm{MgO}$ as a stabiliser. This result proves that the stabiliser type affected the hardness of nanocomposite. Calcium gives a driving force that able to elongate the particle. With a long-shaped particle, the formation between particles will be more solid and stable, which produces improved composite mechanical properties. ${ }^{12}$ Thus in this research, the $\mathrm{CaO}$ stabiliser was improving the mechanical strength better than the $\mathrm{MgO}$ stabiliser.

Despite of these mechanical properties improvement, when compared to the commercially manufactured composites, the hardness values of 


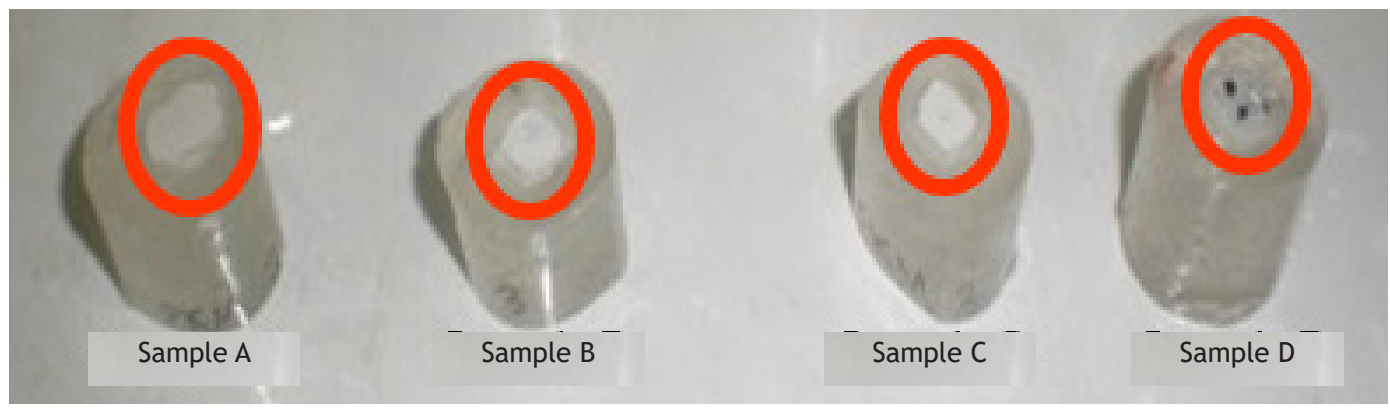

Figure 1. Nanocomposite specimens

Table 1. Hardness values of nanocomposites with PSZ filler

\begin{tabular}{|c|c|c|c|c|c|c|c|c|}
\hline \multirow{2}{*}{ Sample } & \multicolumn{5}{|c|}{ Indentation } & \multirow{2}{*}{$\bar{x}$} & \multirow{2}{*}{ \pm} & \multirow{2}{*}{$S_{\bar{x}}$} \\
\hline & 1 & 2 & 3 & 4 & 5 & & & \\
\hline A & 4.49 & 5.28 & 4.09 & 6.30 & 5.27 & 5.09 & \pm & 0.38 \\
\hline B & 7.06 & 8.86 & 10.04 & 7.23 & 4.35 & 7.51 & \pm & 0.96 \\
\hline C & 7.49 & 7.81 & 9.27 & 7.34 & 8.87 & 8.16 & \pm & 0.39 \\
\hline D & 12.40 & 13.07 & 14.99 & 11.76 & 13.42 & 13.13 & \pm & 0.55 \\
\hline
\end{tabular}

Table 2. Results of ANOVA test; hardness values of all nanocomposite specimens

\begin{tabular}{ccccc}
\hline Groups & Count & Sum & Average & Variance \\
\hline Sample A & 5 & 25.43 & 5.09 & 0.72 \\
Sample B & 5 & 37.54 & 7.51 & 4.62 \\
Sample C & 5 & 40.78 & 8.16 & 0.75 \\
Sample D & 5 & 65.64 & 13.13 & 1.49 \\
\hline
\end{tabular}

Table 3. Results of analysis of variance (ANOVA) between groups

\begin{tabular}{cccccccc}
\hline Source of Variation & SS & df & MS & F & P-value & F crit & Keterangan \\
\hline Between Groups & 170.9 & 3 & 56.95 & \multirow{2}{*}{30.06} & $8.27 \mathrm{E}-07$ & 3.24 & $\begin{array}{c}\mathrm{H}_{0} \text { was } \\
\text { disapproved }\end{array}$ \\
Within Groups & 30.32 & 16 & 1.895 & & & & \\
\hline Total & 201.2 & 19 & & & & \\
\hline
\end{tabular}

the specimens in this research was low. According to McCabe and Walls in 2008, the hardness value of commercially manufactures resin composites were ranged between $30-90 \mathrm{~kg} / \mathrm{mm}^{2}$. The low hardness value of the specimens in this research was probably caused by the composition of filler, coupling agent, and the matrix was not optimized. The composition used in this research was $70 \%$ of filler; $10 \%$ of coupling agent; dan $20 \%$ of matrix. Whilst the composition of the polymer matrix was: 9\% of UDMA; $4 \%$ of HEMA; $3 \%$ of TEGDMA; $3 \%$ of DMAEMA; and $1 \%$ of champoroquinone as photoactivator. This composition probably caused brittle and limited strength specimens. This condition could be caused by too high filler content which leads to the limited bonding between filler and matrix. It is also necessary to establish an appropriate composition of the coupling agent and how to manipulate it to make the coupling agent well-enveloping the filler particles thus a strong bonding between filler and matrix could be obtained. The polymer used was UDMA, which had a lower viscosity than Bis-GMA. This factor also affected the consistency of the matrix mixture and most importantly, the mechanical properties of the nanocomposites. ${ }^{13}$

The low hardness value could also caused by an incomplete polymerisation process. Nanocomposites produced in this research were opaque, which can affected the duration needed for the polymerisation process. Dark-coloured or opaque composites absorb more light thus 
need a longer light-curing duration than the translucent ones. ${ }^{3,5}$ In this research, the lightcuring process with the wavelength of $420-480 \mathrm{~nm}$ was performed in layers with a duration of two minutes for each layer. Two minutes was a long time that can cause patient's discomfort, but makes the polymerisation process incomplete due to the composite's opacity.

The other possibility was the process of compounding the filler, coupling agent, and matrix which was still not perfectly homogeneous. The mixing technique in this research was performed by stirring the mixture with a spatula, then the ultrasonic bath was used for a homogenous mixture. Other mixing technique could be implemented to get a better compound which is more homogenous, to improve the mechanical properties. Non-homogenized nanocomposite can cause an indentation in the hardness measurement which will contact the brittle area thus makes a low hardness value.

\section{CONCLUSION}

The conclusion of this research was the addition of chitosan as coupling agent significantly increasing the mechanical interlocking between filler and matrix thus increasing the nanocomposite hardness value, and the calcia stabiliser produced higher nanocomposite hardness value than the magnesia stabiliser.

\section{REFERENCES}

1. Anusavice KJ. Phillip's science of dental material. $12^{\text {st }}$ ed. St. Louis: Saunders-Elsevier; 2003. p. 96-8,399-440.

2. O'Brien WJ. Dental materials and their selection. $3^{\text {rd }}$ ed. Chicago: Quintessence Publishing Co., Inc.; 2002. p. 113-29.

3. Sakaguchi RL, Powers JM. Craig's restorative dental material. $12^{\text {th }}$ ed. St. Louis: MosbyElsevier; 2006. p. 79-82,190-204.

4. Heymann HO, Swift EJ Jr., Ritter AV. Roberson
TM. Sturdevant's art and science of operative dentistry. $6^{\text {th }}$ ed. St. Louis: Mosby-Elsevier; 2006. p. 500-8.

5. Bandyopadhyay AK. Nano materials. New Delhi: New Age International; 2008. p. 1-2,117-41.

6. Vagkopoulou T, Koutayas SO, Koidis P, Strub JR. Zirconia in dentistry: Part 1. Discovering the nature of an upcoming bioceramic. Eur J Esthet Dent. 2009 Summer;4(2):130-51.

7. Srinivasa PC, Tharanathan RN. Chitin/ chitosan-Safe, ecofriendly packaging materials with multiple potential uses. Food Rev Int. Feb 2007;23(1):53-72. DOI: $10.1080 / 87559120600998163$.

8. Plastics Trends [homepage on internet]. Quebec: Beaulieu C. 2005. Chitin and chitosan. [cited Dec 2017] [about 5 screens]. Available from: http://www. plasticstrends.net/index. php?option=com_content\&view $=$ article\& $\% 20$ $i d=12$ : versatile-and-multiplat formbiomolecules\&catid=13: last - \% 20 months\&ltemid $=28$.

9. Hermawan H. Sintesis dan karakterisasi nanopartikel Yttrium Stabilized Zirconia (YSZ) sebagai dental bridge materials [minor thesis]. Bandung: ITB 2011. p. 19-24.

10. Susanto AA. Effects of materials thickness and length of light exposure on the surface hardness light-cured composite resins. Dent J 2005;38(1):32-35. DOI:10.20473/j.djmkg.v38. i1.p32-35.

11. Shah BL, Selke SE, Walters MB, Heiden PA. Effects of wood flour and chitosan on mechanical, chemical, and thermal properties of polylactide. Polym Comp. Apr 2008;29(6):655-63. DOI: 10.1002/pc.20415.

12. Jung WM, Kang SH, Kim WS, Choi CK. Particle morphology of calcium carbonate precipitated by gas-liquid reaction in a Couette-Taylor reactor. Chem En Sci. Feb 2000;55(4):733-47.

13. McCabe JF, Walls AWG. Applied Dental Materials. $9^{\text {th }}$ ed. Hoboken: Wiley-Blackwell; 2008. p. 13-4,195-224. 